\title{
Cross-sectional and longitudinal associations between sleep duration, sleep quality, and bone stiffness in European children and adolescents
}

\author{
L. Cheng ${ }^{1,2} \cdot$ H. Pohlabeln ${ }^{1} \cdot$ W. Ahrens ${ }^{1,2} \cdot$ P. Russo ${ }^{3} \cdot$ T. Veidebaum ${ }^{4} \cdot$ C. Hadjigeorgiou ${ }^{5} \cdot$ D. Molnár $^{6} \cdot$ \\ M. Hunsberger ${ }^{7}$. S. De Henauw ${ }^{8}$ - L. A. Moreno ${ }^{9}$ - A. Hebestreit ${ }^{1}$ (D) on behalf of the IDEFICS and I.Family consortia
}

Received: 26 June 2020 / Accepted: 18 November 2020 / Published online: 27 November 2020

(C) The Author(s) 2020

\begin{abstract}
Summary In this large perspective cohort among European children and adolescents, we observed that daytime napping was positively associated with bone stiffness, while short or long sleep duration combined with poor sleep quality was associated with less bone stiffness. Our findings are important for obtaining optimal bone stiffness in childhood.

Introduction To examine the cross-sectional and longitudinal associations between sleep duration, sleep quality, and bone stiffness index (SI) in European children and adolescents.

Methods Four thousand eight hundred seventy-one children aged 2-11 years from the IDEFICS study and 861 children aged 615 years from the subsequent I.Family study were included. Sleep duration (i.e., nocturnal sleep and daytime napping) and sleep quality (i.e., irregularly bedtime routine, have difficulty falling asleep and trouble getting up in the morning) were reported by self-administrated questionnaires. Nocturnal sleep duration was converted into age-specific z-scores, and total sleep duration was classified into short, adequate, and long based on the National Sleep Recommendation. Calcaneal SI of both feet were measured using quantitative ultrasound. Linear mixed-effects models with country as a random effect were used, with adjustments for sex, age, pubertal status, family socioeconomic status, physical activity, screen time, body mass index, and daylight duration.

Results Nocturnal sleep duration z-scores were positively associated with SI percentiles among participants with adequate sleep duration at baseline. Moreover, the positive association between daytime napping and SI percentiles was more pronounced in participants with adequate sleep duration at baseline, while at 4-year follow-up was more pronounced in participants with short sleep duration. In addition, extreme sleep duration at baseline predicted lower SI percentiles after 4 years in participants with poor sleep quality.

Conclusion The positive associations between nocturnal sleep, daytime napping and SI depended on total sleep duration. Longterm detrimental effect of extreme sleep duration on SI only existed in individuals with poor sleep quality.
\end{abstract}

Supplementary Information The online version contains

supplementary material available at https://doi.org/10.1007/s00198-020-

05753-x.

A. Hebestreit

hebestr@leibniz-bips.de

1 Leibniz Institute for Prevention Research and Epidemiology - BIPS, Achterstraße 30, 28359 Bremen, Germany

2 Faculty of Mathematics and Computer Science, University of Bremen, Bremen, Germany

3 Institute of Food Sciences, National Research Council, Avellino, Italy

4 Department of Chronic Diseases, National Institute for Health Development, Tallinn, Estonia

5 Research and Education Institute of Child Health, Strovolos, Cyprus
6 Department of Pediatrics, Medical School, University of Pécs, Pécs, Hungary

7 Section for Epidemiology and Social Medicine (EPSO), The Sahlgrenska Academy, University of Gothenburg, Gothenburg, Sweden

8 Department of Public Health, Ghent University, 9000 Ghent, Belgium

9 GENUD (Growth, Exercise, Nutrition and Development) Research Group, Instituto Agroalimentario de Aragón (IA2), Instituto de Investigación Sanitaria Aragón (IIS Aragón), Centro de Investigación Biomédica en Red Fisiopatología de la Obesidad y Nutrición (CIBERObn), University of Zaragoza,

50009 Zaragoza, Spain 
Keywords Bone stiffness index $\cdot$ Child health $\cdot$ Sleep duration $\cdot$ Sleep quality

\section{Introduction}

Sleep duration among European children and adolescents decreased over the last decades, as reported by a systematic review in 2012 [1]. Furthermore, the transition from childhood to adolescence is often accompanied by altered sleep habits, such as irregular bedtime routines and evening-type circadian preference [2]. Researchers have also raised concerns that difficulties in initiating and maintaining sleep are occurring in youth [3, 4], and poor quality of sleeping states (e.g., difficulties falling asleep) and waking states (e.g., trouble getting up in the morning) are equally relevant to health. Even though daytime napping could compensate in part for less nocturnal sleep duration and poor sleep quality, it may also lead to excessive sleep duration as well as less efficient sleep at night time [5]. To date, poor sleep, in terms of extreme duration and poor quality, has been linked to increased risks of poor mental health, obesity, and cardio-metabolic risk among children and adolescents [6].

Emerging evidence has also proposed hypotheses regarding the health effects of sleep on bone metabolism. One potential pathway is the modulation of biological factors related to circadian rhythms [7], sympathetic nervous system [8], and pro-inflammation [9]. Another potential explanation may be the behavioral changes caused by poor sleep such as unhealthy eating behaviors, less physical activity (PA), and more sedentary behaviors (SB) [10], which may further exert detrimental effects on bone accrual. In fact, a number of studies among adults have supported these hypotheses. A recent meta-analysis among middle-aged and elderly adults suggested a U-shaped dose-response with the pooled odds ratios (ORs) of osteoporosis risk of 1.03 (95\% CI 1.01-1.06) for each 1-h sleep reduction among individuals with shorter sleep duration ( $<8 \mathrm{~h} /$ day), and 1.01 (95\% CI 1.00-1.02) for each 1-h sleep increment among individuals with longer sleep duration ( $>8 \mathrm{~h} /$ day) [11]. Two observational studies suggested that poor sleep quality was associated with adulthood osteoporosis measured using Dualenergy X-ray absorptiometry (DXA) [12] and quantitative ultrasound (QUS) [13]. Considering that a large proportion of bone accrual increases during childhood until peak bone mass is achieved during young adulthood [14], the role of sleep on bone health is probably more pronounced in early life. However, few studies have been conducted in children and adolescents, and reported inconsistent results with positive $[15,16]$ or no associations [17] of sleep duration with bone mineral content (BMC) and bone mineral density
(BMD). Besides, little attention has been paid to sleep quality as well as its interrelated effects with nocturnal sleep and daytime napping on bone health.

A better understanding of the relationship between sleep and bone accrual could be helpful to obtain optimal bone strength, which is also considered to be an important prevention strategy for osteoporosis fracture in later life. In order to fill the gaps in previous studies, we aimed to investigate cross-sectional and longitudinal associations of nocturnal sleep duration, daytime napping, and sleep quality with bone stiffness index (SI) measured using QUS from a large population-based cohort of children and adolescents, and to further explore the interactive effects between total sleep duration and sleep quality on SI.

\section{Methods}

\section{Study design and population}

The IDEFICS/I.Family cohort is a multicentre populationbased study which was conducted in eight European countries: Belgium, Cyprus, Estonia, Germany, Hungary, Italy, Spain, and Sweden. The main aim of this cohort was to investigate and prevent diet- and lifestyle-related diseases and disorders among European children and adolescents. The baseline survey (IDEFICS study) was conducted between September 2007 and May 2008, two or more communities in each country whose sociodemographic profile and infrastructure were similar and typical for their region were selected. In total, 16,229 children aged 2 to 9 years participated and fulfilled the inclusion criteria. Two follow-up examinations were further conducted with similar examination modules after 2 years (IDEFICS study) and 6 years (I.Family study) at $2009 / 2010$ and 2013/2014, respectively. The study was conducted according to the standards of the Declaration of Helsinki. Ethical approval was obtained from the ethics committees by all eight study centers. Before children entered the study, parents provided written informed consent. Additionally, children aged 12 years and older gave simplified written consent and children younger than 12 years gave oral consent before each examination. More details on the study design of the IDEFICS/I.Family cohort were published previously [18].

We included data from who participated in the 2009/2010 (in the following referred to as baseline) and 2013/2014 surveys (in the following referred to as follow-up) of the IDEFICS/I.Family cohort, since the sleep variables of interest were only assessed at these two time points. QUS 
measurements were conducted as an optional module in each survey, with 6886 participants at baseline (50.6\%) and 2892 participants at follow-up (30.3\%), respectively. There were no significant differences between participants and nonparticipants for main demographic characteristics (i.e., sex, age, and family socioeconomic status (SES)). We further excluded children and adolescents who (1) had implausible QUS measurements, i.e., absolute difference of SI between the right and left foot exceeded the 97 th percentile (39 units) based on total 8280 measurements; (2) had an indication of impaired bone health at baseline, i.e., with disease or receiving medical treatments affecting the bone; (3) had implausible nocturnal sleep duration, i.e., more than $16 \mathrm{~h}$ per night or less than $5 \mathrm{~h}$ per night; and (4) had incomplete data of covariates, i.e., PA, SB, and pubertal status. Finally, a total of 4871 children at baseline were eligible for the cross-sectional analysis. Of these, 861 participants with complete information at both baseline and follow-up were included in the longitudinal analysis.

\section{Questionnaires}

General questionnaires related to lifestyle behaviors were collected in the IDEFICS/I.Family cohort. Parents were asked to complete the questionnaires on behalf of their children younger than 12 years old, while for older children and adolescents, the questionnaire was self-reported.

\section{Sleep characteristics}

The duration of nocturnal sleep and daytime napping (hours and min) at weekdays/school days and weekend days/vacations was separately recorded. The average of daily nocturnal sleep duration was calculated for each child as follows: (nocturnal sleep duration on weekdays/school days $\times 5+$ nocturnal sleep duration on weekend days/vacations $\times 2$ ) / 7. The value of nocturnal sleep duration for each child was further transformed to an age-specific z-score based on the reference population from I.Family study, in order to consider both children and adolescents. The maximum number of observations with plausible information on age and nocturnal sleep duration was included to obtain the best possible estimates; the years of age were used as categories to calculate age-specific means and standard deviations. Analogously, the average of daily napping time was calculated and expressed as $10 \mathrm{~min} /$ day in order to better interpret the regression coefficients.

We further calculated the total sleep duration by adding up the nocturnal sleep and daytime napping. According to the sleep recommendation from the National Sleep Foundation (NSF) [19], we used the definition of short and long sleep duration as $<10 \mathrm{~h} /$ day and $\geq 13 \mathrm{~h}$ /day for pre-school children aged 2 to $<6$ years, $<9 \mathrm{~h} /$ day and $\geq 11 \mathrm{~h} /$ day for primary school children aged 6 to $<12$ years, $<8 \mathrm{~h} /$ day and $\geq 10 \mathrm{~h} /$ day for adolescents aged 12 to 15 years, respectively.

Additionally, participants were asked to report their typical sleeping habits and daytime condition as follows: (1) do you have a regular bedtime routine (yes $=1$ and no $=0$ ); (2) do you have trouble getting up in the morning (yes $=0$ and no $=1$ ); and (3) do you have difficulty falling asleep (yes $=0$ and no $=$ 1). Similar items were used previously in other large population-based study [20]. We calculated a cumulative score as the sum of these three items (range from 0 to 3 ); individuals scoring 3 were considered as having good sleep quality.

\section{Physical activity and sedentary behavior}

PA level of the participants was recorded as weekly duration of participation in sports clubs. They were asked to report whether the child was a member of a sports club (yes or no); if the answer was yes, then they had to report how many hours and minutes per week. The weekly time spent at sports clubs was calculated by adding hours and minutes and expressed as hours per week (h/w). SB level of the participants was recorded as daily duration of total screen time. Screen time was calculated from reported usual duration of the child watching TV/videos/DVDs and playing computer/game console on a normal weekday and weekend day. For both questions, six response categories were offered and converted into the following scoring system: not at all $=0,<30 \mathrm{~min}=1,<1 \mathrm{~h}=2$, $1-<2 \mathrm{~h}=3,2-3 \mathrm{~h}=4$, and $>3 \mathrm{~h}=5$. Each screen-based SB was calculated separately for weekdays and weekend days by adding up the converted responses of questions as follows: screen-based SB on weekdays/school days $\times 5+$ screenbased SB on weekend days/vacations $\times 2$. The weekly duration of screen time was the total duration of these two screenbased SB and expressed as hours per week $(\mathrm{h} / \mathrm{w})$.

\section{Other covariates}

The age, sex, and SES of participants were obtained from parental questionnaire. The highest education of parents was obtained as a proxy indicator for SES according to the International Standard Classification of Education (ISCED) (low: ISCED levels 0-2; medium: ISCED levels 3-4; high: ISCED levels 5 and higher) [21]. The pubertal status was selfreported by children aged 8 years and older, and was defined as pre-pubertal or pubertal based on voice change in boys and first menstrual period in girls [16]. Sunlight exposure accounts for the main source of vitamin D synthesis [22]; therefore, mean daylight duration $( \pm 0.1 \mathrm{~h})$ for each examination month in each location was calculated using astronomical tables as a proxy for vitamin D level. 


\section{Bone stiffness index}

SI was measured on the left and right calcaneus using QUS (Achilles Lunar Insight TM GE Healthcare, Milwaukee, WI, USA); the reliability study and the methodology of QUS device have previously been described in detail [23]. The measurements and quality control were performed by trained nurses based on the standard operating procedures provided by the manufacturer. The foot was positioned using two different sizes of adapters for participants to keep their calcaneus properly. Before recording each measurement, the preview image of the calcaneus and the region of interest were required to display, in order to avoid measurement error caused by incorrect locations, e.g., the growth plate. The SI was calculated automatically as a percentage (units) based on normalized and scaled values of broadband ultrasound attenuation (BUA, $\mathrm{dB} / \mathrm{MHz}$ ) and speed of sound $(\mathrm{SOS}, \mathrm{m} / \mathrm{s})$ according to: $\mathrm{BSI}=(0.67 * \mathrm{BUA})+$ $(0.28 * \mathrm{SOS})-420$. The value of BUA represents the spatial orientation of the bone trabeculae and increases with greater trabecular complexity. The value of SOS represents the velocity of sound traveling through the bone and increases with greater structures density, and the combination of SOS and BUA was slightly better at predicting bone strength than either parameter alone [24]. The mean SI of the left and right calcaneus measurements was calculated and used in the statistical analysis. For each individual, the SI percentile was calculated additionally as outcome according to age, sex, and height based on the IDEFICS/I.Family reference population. The processing method and the first descriptive results of SI percentile values in the IDEFICS study can be found elsewhere [23], and we additionally provided the sex-specific reference curves for SI percentiles by age for average children based on the $50^{\text {th }}$ height percentile in the IDEFICS/I.Family study in Online Resource (Figure S1).

\section{Anthropometrics measurements}

Physical examinations including body weight and height were measured by trained nurses based on the standard operating procedures. Weight $(\mathrm{kg})$ was measured to the nearest $0.1 \mathrm{~kg}$ using the Tanita scale (BC420 MA for children and BC418 MA for adolescents, Tanita Europe GmbH, Sindelfingen, Germany). Height $(\mathrm{cm})$ was measured to the nearest $0.1 \mathrm{~cm}$ using the calibrated stadiometer (Seca 225/ 213 stadiometer, Birmingham, UK). All examinations were in light clothing without shoes. Body mass index (BMI) was calculated as weight $(\mathrm{kg})$ divided by height $(\mathrm{m})$ squared; the values were transformed to age- and sex-specific z-scores based on Cole et al. [25]

\section{Statistical methods}

Associations between sleep duration, sleep quality, and SI were investigated using linear mixed-effects models, and a random effect for country was added to account for cluster effects. All models were adjusted for age, sex, family SES, daylight duration, and BMI z-scores in each survey. The exposures of sleep duration at baseline and/or follow-up were included as continuous variables (i.e., nocturnal sleep duration z-scores and daytime napping duration) and a dichotomous variable (i.e., fulfilling the sleep recommendation or not) in separate models, to additionally investigate the benefit of meeting sleep recommendation on SI percentiles. The exposure of sleep quality at baseline and/or follow-up was included as a dichotomous variable (i.e., good and poor). The outcome for cross-sectional analyses was baseline SI percentile, with additional adjustments for baseline duration of PA and SB. The outcome for longitudinal analyses was SI percentile at follow-up, with additional adjustments for SI percentile at baseline, pubertal status at follow-up, and average durations of PA and SB at both surveys. Since sleep duration and sleep quality may have interactive effects on SI, we further stratified the whole group by total sleep duration and quality, to investigate the different effects of interests across stratifications.

All the statistical analyses were carried out with the Statistical Analysis System (SAS) software package (Version 9.4; SAS Institute, Cary, NC). Regression coefficients $(\beta), 95 \%$ confidence intervals $(95 \% \mathrm{CIs})$, and $p$ values were calculated. The significance level was set at $\alpha=0.05$ (2sided tests); multiple testing was further adjusted and cited in footnotes if $p$ values exceed 0.05 according to Holm's sequential Bonferroni procedure [26].

\section{Results}

\section{Descriptive analyses}

At baseline, 4871 participants consist of 742 pre-school children and 4129 primary school children were included in crosssectional analyses. Of these, 861 participants consist of 352 primary school children and 509 adolescents from 5 participating centers were further included in longitudinal analyses after a 4-year follow-up. The proportion of boys ( $47.0 \%$ vs. $50.5 \%, p=0.06)$ and mean age ( 8.28 years vs. 8.20 years, $\mathrm{p}=$ 0.19 ) of longitudinal analytic sample were comparable to children who did not provide follow-up data, but less participants were classified as low (8.4\% vs. $9.1 \%)$ and high SES (30.0\% vs. $38.1 \%), p<0.001$. More details of demographic characteristics are shown in Table 1; additional results of Pearson's correlations and $95 \%$ CIs between co-variables, sleep exposures, and bone stiffness index can be found in Online Resource (Table S1). 
Table 1 Descriptive characteristics of the study population

\begin{tabular}{|c|c|c|c|c|c|c|}
\hline & \multicolumn{3}{|l|}{ Baseline } & \multicolumn{3}{|l|}{ Follow-up } \\
\hline & $\begin{array}{l}\text { Whole group } \\
N=4871\end{array}$ & $\begin{array}{l}2 \text { to }<6 \text { years } \\
N=742\end{array}$ & $\begin{array}{l}6 \text { to }<12 \text { years } \\
N=4129\end{array}$ & $\begin{array}{l}\text { Whole group } \\
N=861\end{array}$ & $\begin{array}{l}6 \text { to }<12 \text { years } \\
N=352\end{array}$ & $\begin{array}{l}12 \text { to } 15 \text { years } \\
N=509\end{array}$ \\
\hline Age (mean, SD) & $8.21(1.82)$ & $5.17(0.64)$ & $8.76(1.37)$ & $12.13(1.75)$ & $10.27(1.01)$ & $13.42(0.64)$ \\
\hline \multicolumn{7}{|l|}{$\operatorname{Sex}(N, \%)$} \\
\hline Boys & $2431(49.9)$ & $370(49.9)$ & $2061(49.9)$ & $406(47.2)$ & $161(45.7)$ & $245(48.1)$ \\
\hline Girls & $2440(50.1)$ & $372(50.1)$ & $2068(50.1)$ & $455(52.8)$ & $191(54.3)$ & $264(51.9)$ \\
\hline \multicolumn{7}{|l|}{ Puberty status $(N, \%)^{\mathrm{a}}$} \\
\hline Pre or early pubertal & / & l & / & 447 (51.9) & $297(84.4)$ & $150(29.5)$ \\
\hline Pubertal & / & / & / & $414(48.1)$ & $55(15.6)$ & $359(70.5)$ \\
\hline \multicolumn{7}{|l|}{$\operatorname{SES}(N, \%)$} \\
\hline Low & $436(9.0)$ & $54(7.3)$ & $382(9.3)$ & $54(6.3)$ & $23(6.5)$ & $31(6.1)$ \\
\hline Medium & $2649(54.4)$ & $364(49.1)$ & $2285(55.3)$ & $434(50.4)$ & $188(53.4)$ & $246(48.3)$ \\
\hline High & $1786(36.7)$ & $324(43.7)$ & $1462(35.4)$ & $373(43.3)$ & $141(40.1)$ & $232(45.6)$ \\
\hline \multicolumn{7}{|l|}{ Country $(N, \%)^{\mathrm{b}}$} \\
\hline Belgium & $325(6.7)$ & $42(5.7)$ & $283(6.9)$ & l & l & l \\
\hline Cyprus & $141(2.9)$ & $52(7.0)$ & $89(2.2)$ & $8(0.9)$ & $5(1.4)$ & $3(0.6)$ \\
\hline Estonia & $652(13.4)$ & $8(1.1)$ & $644(15.6)$ & $155(18.0)$ & $0(0)$ & $155(30.5)$ \\
\hline Germany & $779(16.0)$ & $122(16.4)$ & 657 (15.9) & $259(30.1)$ & $142(40.3)$ & $117(23.0)$ \\
\hline Hungary & 677 (13.9) & 140 (18.9) & $537(13.0)$ & I & I & I \\
\hline Italy & $1208(24.8)$ & $186(25.1)$ & $1022(24.8)$ & $251(29.2)$ & $106(30.1)$ & $145(28.5)$ \\
\hline Spain & $771(15.8)$ & 138 (18.6) & $633(15.3)$ & $188(21.8)$ & $99(28.1)$ & 89 (17.5) \\
\hline Sweden & $318(6.5)$ & $54(7.3)$ & $264(6.4)$ & I & I & I \\
\hline
\end{tabular}

${ }^{\text {a }}$ Pubertal status was not available at baseline survey and indicated with "/"

${ }^{\mathrm{b}}$ Countries which did not participate in quantitative ultrasound module were indicated with "/"

At baseline, the average daily nocturnal sleep duration was $9.89 \mathrm{~h}$; the median value of reported daily daytime napping was $60 \mathrm{~min}$. There were $11.2 \%$ participants defined as short sleep duration and $6.0 \%$ participants defined as long sleep duration. Overall, $44.6 \%$ of the participants were defined as poor sleep quality. At follow-up, the average daily nocturnal sleep duration was $9.10 \mathrm{~h}$; the median value of reported daily daytime napping was $31.4 \mathrm{~min}$. The proportions of short and long sleep duration were $16.7 \%$ and $8.8 \%$, respectively; $58.8 \%$ of participants were reported having poor sleep quality. Furthermore, the average bone stiffness index was 81.91 units at baseline and 91.22 units at follow-up. More details regarding exposures, outcomes, and covariates among pre-school children, primary school children, and adolescents in each survey were shown in Table 2.

\section{Associations between nocturnal sleep, daytime napping, sleep quality, and SI percentiles}

In the whole group, no cross-sectional associations between nocturnal sleep duration z-scores, sleep quality, and SI percentiles were observed. Daytime napping duration was positively associated with SI percentiles ( $\beta=0.78,95 \%$ CI: $0.43,1.14, p<0.001)$, and this association was independent of negative effect of screen time and positive effect of sports club on SI percentiles as shown in Online Resource (Table S2). After stratifying by total sleep duration categories, we found that nocturnal sleep duration $\mathrm{z}$ scores were positively associated with SI percentiles in participants with adequate sleep duration $(\beta=1.81$, 95\%CI: $0.55,3.07$, $p=0.005)$, and effect size was even larger, however not statistically significant, in participants with long sleep duration $(\beta=$ 3.71 , 95\%CI: $-2.28,9.70, p=0.22$ ). Nevertheless, the positive association between daytime napping and SI percentiles was statistically significant only in participants with adequate sleep duration $(\beta=1.19,95 \% \mathrm{CI}: 0.76,1.61, p<0.001)$, and was more pronounced but not statistically significant in participants with short sleep duration $(\beta=1.27,95 \% \mathrm{CI}:-1.14,3.69, p=0.30)$ (Table 3).

After 4 years, we found that only follow-up daytime napping was positively associated with follow-up SI percentiles $(\beta=0.84$, 95\%CI: $0.14,1.53, p=0.02$ ), and it was not influenced by the positive effect of sports club as shown in Online Resource (Table S3), but only existed in participants with short sleep duration after stratification $(\beta=2.42,95 \% \mathrm{CI}$ : $0.98,3.85, p=$ 0.001 ). Even though there were no statistically significant associations between sleep quality and SI percentiles in all groups after 4 years, we observed that participants with poor sleep 
Table 2 Baseline and follow-up characteristics of exposures, outcomes, and covariates

\begin{tabular}{|c|c|c|c|c|c|c|}
\hline & \multicolumn{3}{|l|}{ Baseline } & \multicolumn{3}{|l|}{ Follow-up } \\
\hline & $\begin{array}{l}\text { Whole group } \\
N=4871\end{array}$ & $\begin{array}{l}2 \text { to }<6 \text { years } \\
N=742\end{array}$ & $\begin{array}{l}6 \text { to }<12 \text { years } \\
N=4129\end{array}$ & $\begin{array}{l}\text { Whole group } \\
N=861\end{array}$ & $\begin{array}{l}6 \text { to }<12 \text { years } \\
N=352\end{array}$ & $\begin{array}{l}12 \text { to } 15 \text { years } \\
N=509\end{array}$ \\
\hline \multicolumn{7}{|l|}{ Sleep duration } \\
\hline $\begin{array}{l}\text { Nocturnal sleep duration (hours/day), } \\
\quad \text { (mean, SD) }\end{array}$ & $9.89(0.80)$ & $10.28(0.85)$ & $9.82(0.77)$ & $9.10(1.01)$ & $9.62(0.71)$ & $8.75(1.03)$ \\
\hline $\begin{array}{l}\text { Nocturnal sleep duration z-scores, } \\
\quad(\text { mean, SD) }\end{array}$ & $0.33(0.97)$ & $0.48(0.96)$ & $0.31(0.97)$ & $0.09(0.99)$ & $0.26(0.92)$ & $-0.03(1.02)$ \\
\hline Had daytime napping $(n, \%)$ & $522(10.7)$ & 237 (31.9) & $285(6.9)$ & $119(13.8)$ & $25(7.1)$ & $94(18.5)$ \\
\hline $\begin{array}{l}\text { Daytime napping duration (10 } \\
\text { min/day), (median interquartile } \\
\text { range) }\end{array}$ & $\begin{array}{l}6.00 \\
\quad(2.57-9.00)\end{array}$ & $\begin{array}{l}8.14 \\
\quad(4.29-10.71)\end{array}$ & $\begin{array}{l}4.29 \\
\quad(2.57-6.43)\end{array}$ & $\begin{array}{l}3.14 \\
\quad(1.71-7.29)\end{array}$ & $\begin{array}{l}2.29 \\
\quad(1.71-7.29)\end{array}$ & $\begin{array}{l}3.82 \\
\quad(1.71-7.29)\end{array}$ \\
\hline \multicolumn{7}{|l|}{ Total sleep recommendation $(n, \%)$} \\
\hline Short & $545(11.2)$ & $126(17.0)$ & $419(10.1)$ & $144(16.7)$ & $54(15.3)$ & $90(17.7)$ \\
\hline Adequate & $4032(82.8)$ & $610(82.2)$ & $3422(82.9)$ & $641(74.5)$ & $289(82.1)$ & $352(69.2)$ \\
\hline Long & $294(6.0)$ & $6(0.8)$ & $288(7.0)$ & $76(8.8)$ & $9(2.6)$ & $67(13.2)$ \\
\hline \multicolumn{7}{|l|}{ Sleep quality $(n, \%)$} \\
\hline Had an unregularly bedtime routine & $1144(23.5)$ & $171(23.1)$ & $973(23.6)$ & $239(27.8)$ & $48(13.6)$ & $191(37.5)$ \\
\hline Had difficulty to fall asleep & $427(8.8)$ & $55(7.4)$ & $372(9.0)$ & $148(17.2)$ & $39(11.1)$ & $109(21.4)$ \\
\hline Had trouble getting up & $1117(22.9)$ & $146(19.7)$ & $971(23.5)$ & $359(41.7)$ & $101(28.7)$ & $258(50.7)$ \\
\hline Overall poor sleep quality & $2172(44.6)$ & $304(41.0)$ & $1868(45.2)$ & $506(58.8)$ & $147(41.8)$ & $359(70.5)$ \\
\hline \multicolumn{7}{|l|}{ Quantitative ultrasound } \\
\hline Bone stiffness index, (mean, SD) & $81.91(13.19)$ & $81.06(16.79)$ & $82.06(12.43)$ & $91.22(16.38)$ & $82.82(12.78)$ & $97.03(16.09)$ \\
\hline $\begin{array}{l}\text { Bone stiffness index percentiles, } \\
\text { (mean, SD) }\end{array}$ & $46.83(28.34)$ & $51.62(30.59)$ & $45.97(27.84)$ & $53.89(28.98)$ & $42.47(28.67)$ & $61.79(26.48)$ \\
\hline \multicolumn{7}{|l|}{ Anthropometric measures } \\
\hline Height (cm), (mean, SD) & $131.19(12.28)$ & $112.78(6.52)$ & $134.50(9.92)$ & $154.23(12.06)$ & $143.91(8.84)$ & $161.37(8.21)$ \\
\hline Weight (kg), (mean, SD) & $30.80(9.79)$ & $20.53(4.10)$ & $32.64(9.36)$ & $48.44(13.90)$ & $39.32(10.89)$ & $54.75(12.16)$ \\
\hline Body mass index, (mean, SD) & $17.50(3.30)$ & $16.03(2.16)$ & $17.77(3.39)$ & $20.05(4.00)$ & $18.77(3.80)$ & $20.93(3.90)$ \\
\hline Body mass index z-scores, (mean, SD) & $0.52(1.21)$ & $0.26(1.30)$ & $0.56(1.18)$ & $0.62(1.08)$ & $0.61(1.13)$ & $0.62(1.05)$ \\
\hline \multicolumn{7}{|l|}{ Health behaviors } \\
\hline Screen time (hours/week), (mean, SD) & $13.90(7.69)$ & $10.88(6.46)$ & $14.44(7.77)$ & $16.41(10.33)$ & $12.49(6.81)$ & $19.12(11.43)$ \\
\hline Sports club (hours/week), (mean, SD) & $1.88(2.14)$ & $0.75(1.25)$ & $2.08(2.20)$ & $2.72(2.81)$ & $2.43(2.24)$ & $2.92(3.13)$ \\
\hline
\end{tabular}

${ }^{a}$ Calculated only for participants who reported had daytime napping

quality tended to have lower SI percentiles compared to their counterparts in short $(\beta=-10.17,95 \% \mathrm{CI}:-21.94,1.61, p=$ $0.09)$ and long sleep duration group $(\beta=-4.99,95 \% \mathrm{CI}:-22.75$, $12.78, p=0.56$ ), respectively (Table 4 ). The combined effect size was $-11.61(95 \% \mathrm{CI}:-21.09,-2.12, p=0.02)$ if we merged short and long sleep duration into one group with participants who did not fulfill the sleep recommendation.

\section{Associations between meeting NSF sleep recommendation and SI percentiles}

At baseline, there was no statistically significant difference on SI percentile between children who fulfilled the sleep recommendation and who did not. However, extreme total sleep duration at baseline predicted lower SI percentiles after 4 years compared to their counterparts when participants simultaneously had poor sleep quality at baseline $(\beta=-8.09$, 95\%CI: $-13.39,-2.79, p=0.003$ ) (Table 5). As shown in Online Resource (Table S4), four interaction terms in the crosssectional model and eight in the longitudinal model were separately introduced to the main effects in the whole group, one of which was statistically significant, i.e., the interaction between extreme total sleep duration at baseline and average screen time $(\beta=-0.52,95 \% \mathrm{CI}:-1.02,-0.03, p=0.04)$. Specifically, screen time has a stronger detrimental effect on SI percentile in children with extreme total sleep duration.

\section{Discussion}

We observed a positive cross-sectional association between nocturnal sleep duration and SI only in participants with 
Table 3 Cross-sectional associations between sleep characteristics and bone stiffness index percentiles in 2009/10, stratified by total sleep duration ${ }^{\mathrm{a}}$

\begin{tabular}{|c|c|c|c|c|c|c|c|c|}
\hline & \multirow{2}{*}{\multicolumn{2}{|c|}{$\begin{array}{l}\text { Whole group } \\
(N=4871)\end{array}$}} & \multirow{2}{*}{\multicolumn{2}{|c|}{$\begin{array}{l}\text { Short sleep duration } \\
(N=545)\end{array}$}} & \multirow{2}{*}{\multicolumn{2}{|c|}{$\begin{array}{l}\text { Adequate sleep duration } \\
(N=4032)\end{array}$}} & \multirow{2}{*}{\multicolumn{2}{|c|}{$\frac{\text { Long sleep duration }}{(N=294)}$}} \\
\hline & & & & & & & & \\
\hline & $\beta(95 \% \mathrm{CI})$ & $p$ value & $\beta(95 \% \mathrm{CI})$ & $\begin{array}{l}p \\
\text { value }\end{array}$ & $\beta(95 \% \mathrm{CI})$ & $p$ value & $\beta(95 \% \mathrm{CI})$ & $\begin{array}{l}p \\
\text { value }\end{array}$ \\
\hline $\begin{array}{l}\text { Nocturnal sleep duration } \\
\text { z-scores }\end{array}$ & $0.26(-0.63,1.14)$ & 0.57 & $\begin{array}{l}-1.25(-4.82, \\
2.31)\end{array}$ & 0.49 & $1.81(0.55,3.07)$ & 0.005 & $\begin{array}{l}3.71(-2.28 \\
9.70)\end{array}$ & 0.22 \\
\hline Daytime napping & $0.78(0.43,1.14)$ & $\begin{array}{l}p< \\
0.001\end{array}$ & $1.27(-1.14,3.69)$ & 0.30 & $1.19(0.76,1.61)$ & $\begin{array}{l}p< \\
0.001\end{array}$ & $\begin{array}{c}0.36(-1.05 \\
1.78)\end{array}$ & 0.61 \\
\hline \multicolumn{9}{|l|}{ Sleep quality } \\
\hline Poor vs. good (reference) & $\begin{array}{l}-0.44(-2.09 \\
1.22)\end{array}$ & 0.61 & $0.87(-4.12,5.86)$ & 0.73 & $\begin{array}{l}-0.88(-2.70 \\
0.93)\end{array}$ & 0.34 & $\begin{array}{c}1.42(-5.84 \\
8.69)\end{array}$ & 0.70 \\
\hline
\end{tabular}

All models were adjusted for sex, age, family socioeconomic status, screen time, time spent at sports clubs, BMI z-scores, and daylight duration, with a random effect for country

${ }^{a}$ Based on the sleep recommendation from the National Sleep Foundation

adequate sleep duration. In general, the positive association between daytime napping and SI was more pronounced in participants with short and adequate sleep duration. Moreover, extreme sleep duration at baseline predicted lower SI over the 4 years of follow-up in participants with poor sleep quality. Besides, a negative association of SB and a positive association of PA with SI were observed, which are consistent with previous IDEFICS/I.Family findings [27, 28]. However, these known factors influencing bone development did not modify the associations between sleep exposures and SI in
Table 4 Longitudinal associations between sleep characteristics and bone stiffness index percentiles in 2013/14, stratified by total sleep duration ${ }^{\text {a }}$

\begin{tabular}{|c|c|c|c|c|c|c|c|c|}
\hline & \multicolumn{2}{|c|}{ Whole group } & \multicolumn{2}{|c|}{ Short sleep duration } & \multicolumn{2}{|c|}{$\begin{array}{l}\text { Adequate sleep } \\
\text { duration }\end{array}$} & \multicolumn{2}{|l|}{$\begin{array}{l}\text { Long sleep } \\
\text { duration }\end{array}$} \\
\hline & $(N=861)$ & & $(N=101)$ & & $(N=722)$ & & $(N=38)$ & \\
\hline & $\begin{array}{l}\beta \\
\quad(95 \%- \\
\mathrm{CI})\end{array}$ & $\begin{array}{l}p \\
\mathrm{v}- \\
\text { al- } \\
\text { ue }\end{array}$ & $\begin{array}{l}\beta \\
\quad(95 \% \mathrm{C}- \\
\mathrm{I})\end{array}$ & $\begin{array}{l}p \\
\text { v- } \\
\text { al- } \\
\text { ue }\end{array}$ & $\begin{array}{l}\beta \\
\quad(95 \%- \\
\mathrm{CI})\end{array}$ & $\begin{array}{l}p \\
\text { v- } \\
\text { al- } \\
\text { ue }\end{array}$ & $\begin{array}{l}\beta \\
\quad(95 \% \mathrm{C}- \\
\mathrm{I})\end{array}$ & $\begin{array}{l}p \\
\text { v- } \\
\text { al- } \\
\text { ue }\end{array}$ \\
\hline $\begin{array}{l}\text { Baseline nocturnal } \\
\text { sleep duration } \\
\text { Z-scores }\end{array}$ & $\begin{array}{c}-0.43(- \\
2.30 \\
1.44)\end{array}$ & 0.65 & $\begin{array}{c}-0.17(- \\
10.53 \\
10.18)\end{array}$ & 0.97 & $\begin{array}{c}-1.31(- \\
3.85 \\
1.23)\end{array}$ & 0.31 & $\begin{array}{c}-9.52(- \\
24.27 \\
5.23)\end{array}$ & 0.19 \\
\hline $\begin{array}{l}\text { Baseline daytime } \\
\text { napping }\end{array}$ & $\begin{array}{c}-1.06(- \\
2.05,- \\
0.07)\end{array}$ & $\underset{\mathrm{c}}{0.04}$ & $\begin{array}{c}-4.80(- \\
14.78 \\
5.18)\end{array}$ & 0.34 & $\begin{array}{c}-1.03(- \\
2.48 \\
0.42)\end{array}$ & 0.16 & $\begin{array}{c}-1.73(- \\
5.05 \\
1.58)\end{array}$ & 0.29 \\
\hline $\begin{array}{l}\text { Follow-up } \\
\text { nocturnal sleep } \\
\text { duration z-scores }\end{array}$ & $\begin{array}{c}-0.73(- \\
2.35 \\
0.89)\end{array}$ & 0.38 & $\begin{array}{r}1.11(- \\
4.65 \\
6.87)\end{array}$ & 0.70 & $\begin{array}{c}-0.53(- \\
2.30 \\
1.24)\end{array}$ & 0.56 & $\begin{array}{c}-0.36(- \\
6.06 \\
5.34)\end{array}$ & 0.90 \\
\hline $\begin{array}{l}\text { Follow-up daytime } \\
\text { napping }\end{array}$ & $\begin{array}{l}0.84 \\
\quad(0.14 \\
1.53)\end{array}$ & 0.02 & $\begin{array}{l}2.42 \\
\quad(0.98 \\
3.85)\end{array}$ & 0.001 & $\begin{array}{r}0.37(- \\
0.47 \\
1.21)\end{array}$ & 0.39 & $\begin{array}{r}0.52(- \\
3.13 \\
4.18)\end{array}$ & 0.77 \\
\hline \multicolumn{9}{|l|}{ Sleep quality ${ }^{\mathrm{b}}$} \\
\hline $\begin{array}{l}\text { Poor vs. good } \\
\text { (reference) }\end{array}$ & $\begin{array}{c}-1.29(- \\
4.98 \\
2.40)\end{array}$ & 0.49 & $\begin{array}{c}-10.17(- \\
21.94 \\
1.61)\end{array}$ & 0.09 & $\begin{array}{r}0.12(- \\
3.85 \\
4.08)\end{array}$ & 0.95 & $\begin{array}{r}-4.99(- \\
22.75 \\
12.78)\end{array}$ & 0.56 \\
\hline
\end{tabular}

All models were adjusted for bone stiffness index percentiles at baseline, sex, age, family socioeconomic status, pubertal status, BMI z-scores, and daylight duration at follow-up as well as average screen time and time spent at sports clubs at both surveys

${ }^{\mathrm{a}}$ Based on the sleep recommendation from the National Sleep Foundation

${ }^{\mathrm{b}}$ Good sleep quality was defined as fulfilling at both baseline and follow-up

${ }^{c} p \geq 0.05$ after adjustment for multiple testing according to Holm's sequential Bonferroni procedure 
Table 5 Cross-sectional and longitudinal associations between meeting sleep guidelines ${ }^{\text {a }}$ and bone stiffness index percentiles, stratified by sleep quality

\begin{tabular}{|c|c|c|c|c|c|c|}
\hline & \multicolumn{2}{|l|}{ Whole group } & \multicolumn{2}{|l|}{ Poor sleep quality } & \multicolumn{2}{|l|}{ Good sleep quality } \\
\hline & $\beta(95 \% \mathrm{CI})$ & $p$ value & $\beta(95 \% \mathrm{CI})$ & $p$ value & $\beta(95 \% \mathrm{CI})$ & $p$ value \\
\hline Cross-sectional models & $N=4871$ & & $N=2172$ & & $N=2699$ & \\
\hline Short or long vs. adequate (reference) & $-0.49(-2.46,1.47)$ & 0.62 & $0.82(-1.91,3.55)$ & 0.56 & $-1.89(-4.73,0.94)$ & 0.19 \\
\hline Longitudinal models & $N=861$ & & $N=405$ & & $N=456$ & \\
\hline Baseline short or long vs. adequate (reference) & $-3.45(-7.61,0.70)$ & 0.10 & $-8.09(-13.39,-2.79)$ & 0.003 & $1.28(-5.17,7.73)$ & 0.70 \\
\hline Follow-up short or long vs. adequate (reference) & $-0.55(-4.09,2.99)$ & 0.76 & $0.49(-4.26,5.25)$ & 0.84 & $-3.08(-8.31,2.14)$ & 0.25 \\
\hline
\end{tabular}

All cross-sectional models were adjusted for sex, age, family socioeconomic status, screen time, time spent at sports clubs, BMI z-scores, and daylight duration, with a random effect for country

All longitudinal models were adjusted for bone stiffness index percentiles at baseline, sex, age, family socioeconomic status, pubertal status, BMI zscores, and daylight duration at follow-up as well as average screen time and time spent at sports clubs at both surveys

All whole models were additionally adjusted for sleep quality

${ }^{a}$ Based on the sleep recommendation from the National Sleep Foundation

the present study. In addition, we found extreme sleep duration had an interactive effect on the association between screen time and SI, suggesting that sleep duration should also be taken into consideration in further studies on behavioral risk factors for bone health.

To our best knowledge, there were only three studies investigating the associations between sleep duration and bone density measured by DXA among children and adolescents and reporting conflicting results: a cross-sectional study among 4-12 year-old children found positive associations of long nocturnal sleep duration and daytime napping with total BMC [15]. Another study conducted among 6-18 year-old Japanese students reported that habitual napping rather than nocturnal sleep duration was positively associated with BMD at the distal forearm of the non-dominant side [16]. The last, a longitudinal study using compositional time of $24 \mathrm{~h}$ day, reported that total sleep duration was not related to BMC and BMD [17]. QUS, as a fast, radiation-free and cost-effective technique, not only offers better accessibility for large-scale epidemiological studies particularly involving healthy children and adolescents but also provides some information on the structural and geometric properties of the bone in addition to bone density measured by DXA. The predictive values of both BUA and SOS for osteoporotic fracture have been supported by a systematic review on prospective studies, albeit decreased with time [29]. Some researchers propose to use more sophisticated QUS indices, e.g., SI. Compared with using BUA and SOS alone, SI showed more sensitivity for subjects with low BMD [30] and better long-term precision to monitor the treatment effect of therapies [31, 32]. However, there are still some concerns on the QUS methodology because of the poor knowledge on bone properties reflected by QUS parameters, the influence of body size, and technological diversity among QUS devices and indices [24]. Therefore, the comparison of our study with previous research is limited and our results should be carefully interpreted.

In the present study, we found that longer nocturnal sleep duration would not be beneficial to bone health if children had inadequate total sleep duration. In contrast, more daytime napping could make up for the deleterious effect of inadequate total sleep duration on bone. However, our results were in contrast to the findings from previous studies in adults, which suggested that daytime napping duration was a risk factor of lower BMD $[33,34]$. According to previous systematic reviews regarding other health effects of daytime napping, the risks of detrimental outcomes (i.e., cardiovascular disease, and type diabetes and metabolic syndrome) showed a J-curve dose-response with no effect [35] or decreases [36] up to about $40 \mathrm{~min} /$ day, and then followed by sharp increases. Moreover, a study conducted in American high school students suggested that only specific time period of taking naps (e.g., after $2 \mathrm{pm}$ ) was related to increasing inflammatory factors [37]. However, only about $6 \%$ of the children reported their daytime napping was more than $40 \mathrm{~min} /$ day in our sample. These results indicated that acceptable duration of daytime napping may be good for bone health in children and adolescents who did not have long sleep duration. However, the optimal threshold and timing of napping are still needed to be confirmed.

Healthy sleep consists of adequate duration and good quality. Although individuals with extreme sleep duration (short or long) tend to have poor sleep quality and vice versa, it is still possible that some individuals naturally need less or more sleep compared to others, only if good sleep quality is maintained under individually preferred sleep duration [38]. On the other hand, individuals with poor sleep quality also may partly compensate by keeping adequate sleep duration. Nonetheless, relatively few studies simultaneously examined the effects of extreme sleep duration and sleep quality. In order to preclude the interplay of sleep duration and quality in the present study, 
we explored the associations stratified by sleep duration and sleep quality, suggested that the associations of sleep duration and quality with bone health may be interrelated. These findings were supported by previous studies in adults. For example, Zeng et al. [39] reported that long sleep duration was a risk factor for poor quality of life in patients with type 2 diabetes mellitus who reported poor sleep quality. In contrast, Chen et al. [33] found the association between sleep duration and osteoporosis was most pronounced in postmenopausal women reported good sleep quality. Given the limited and conflicting evidence, the interactive effect between sleep duration and sleep quality on bone is still unknown.

Experimental sleep deprivation studies have demonstrated that sleep restriction may lead to increase of bone resorption markers and decrease of bone formation markers, thereby impacting the bone mass accrual [40,41]. Compared to the detrimental effects of short sleep duration, evidence of long sleep duration is still lack among youth, and the underlying mechanism for adverse effects of long sleep duration on health is rarely investigated because of the difficulty to conduct experimental studies. However, a recent systematic review suggested that long sleep duration, but not short sleep duration, was associated with increased inflammatory factors [9]. Moreover, long sleep duration may decrease daily exercises and thus results in less bone stimulation from mechanical loading [42]. Furthermore, extreme sleep duration and poor quality always paralleled with the poor sleep efficiency and interruption of circadian rhythm [43]. Growth hormone (GH) levels are increased during sleep period. GH and insulin-like growth factor 1 (IGF-1) have been demonstrated to stimulate osteoblasts in the bone, and GH also effects musculoskeletal system directly as well as through mediating IGF-1 levels [44]. In addition, the circadian rhythm is related to hypothalamic-pituitary-adrenal axis which is typically relates to the release of cortisol. High level of cortisol can exert detrimental effects on the musculoskeletal system directly and by inhibiting GH and IGF-1 [44, 45]. Considering that the increases of extreme sleep duration and poor sleep quality have raised a concern from early life span, more perspective studies are needed to establish causality as well as the underlying mechanisms on bone health.

The main strength of the present study is that we fill the research gap regarding the associations and interplays of nocturnal sleep duration, daytime napping, and sleep quality with SI. Moreover, the prospective study design, the standardized measures providing harmonized data across eight European countries, and the large sample size covering children from 2 to 15 years old strengthen our findings. The deep phenotyping also allows consideration of a number of important confounders, i.e., family SES, pubertal status, BMI, PA, and SB. However, some limitations should be acknowledged. First, the QUS measurement was only available in a subgroup with decreasing sample size over the 4 years of follow-up, which may cause selective bias in data interpretation. Second, sleep duration was reported by parents or adolescents, and sleep quality was estimated from only three sleep characteristics. Finally, we did not have information regarding some possible confounders, e.g., weight-bearing exercises and calcium intake. Instead, we used proxy indicators of reported types of sport in sports club (moderate or high mechanical loads vs. no or low mechanical loads) and milk and dairy products consumption (frequency/week). However, no modifying effects were observed in the exploratory analysis stage; hence, we did not include them in the final models in order to maintain the sample size.

In conclusion, we observed that for every $10 \mathrm{~min} /$ day increase in daytime napping was associated with approximately 1 unit increase in SI percentiles, and it was even more beneficial for individuals who had short sleep duration according to NSF sleep recommendation. Furthermore, the associations of sleep duration and sleep quality with calcaneus SI may partly depend on each other. We suggest that children and adolescents should follow the NSF sleep recommendation in order to maximize bone strength during growth, especially for those who had poor sleep quality measured by no regular bedtime routine, had trouble getting up in the morning and difficulty falling asleep.

Acknowledgments We are grateful to all the children and their parents who took part in the IDEFICS and I.Family cohort. Thanks for the support of participating school boards, headmasters, teachers, school staffs, and communities, and for the effort of the entire IDEFICS/I.Family research team. Lan Cheng personally wishes to thank for financial support from the China Scholarship Council on her PhD study.

Funding Open Access funding enabled and organized by Projekt DEAL. This work was a part of the IDEFICS study (https://www.idefics.eu) funded by the European Commission within the Sixth RTD Framework Programme Contract No. 016181 (FOOD) and the I.Family study (https:// www.ifamilystudy.eu/) funded by the European Commission within the Seventh RTD Framework Programme Contract No. 266044.

Data availability The datasets of the present study are not publicly available since it is highly sensitive data collected in young children. Interested researchers can contact the IDEFICS and I.Family consortia (http://www. ideficsstudy.eu/Idefics/ and https://www.ifamilystudy.eu/) for possible data access.

\section{Compliance with ethical standards}

\section{Conflict of interest None.}

Ethics approval Ethical approval was obtained from the ethics committees for all participating centers in each country: Ethics Committee, University Hospital, Gent, Belgium; Cyprus National Bioethics Committee, Nicosia, Cyprus; Tallinn Medical Research Ethics Committee, Tallinn, Estonia; Ethics Committee of the University of Bremen, Bremen, Germany; Egészségügyi Tudományos Tanács, Pécs, Hungary; Azienda Sanitaria Locale Avellino Comitato Etico, Avellino, Italy; Regionala Etikprövningsnämnden i Göteborg, Gothenburg, Sweden; Comité Ético de Investigación Clínica de Aragón, Zaragoza, 
Spain. All the examinations were performed in accordance with the ethical standards as laid down in the 1964 Declaration of Helsinki.

Consent to participate All parents signed informed consent, in addition, children aged 12 years and older gave simplified written consent and children younger than 12 years gave oral consent prior to the examinations in addition to the signed parental consent.

\section{Consent for publication Not applicable}

Code availability All the statistical analyses were carried out with the Statistical Analysis System (SAS) software package (Version 9.4; SAS Institute, Cary, NC).

Open Access This article is licensed under a Creative Commons Attribution-NonCommercial 4.0 International License, which permits any non-commercial use, sharing, adaptation, distribution and reproduction in any medium or format, as long as you give appropriate credit to the original author(s) and the source, provide a link to the Creative Commons licence, and indicate if changes were made. The images or other third party material in this article are included in the article's Creative Commons licence, unless indicated otherwise in a credit line to the material. If material is not included in the article's Creative Commons licence and your intended use is not permitted by statutory regulation or exceeds the permitted use, you will need to obtain permission directly from the copyright holder. To view a copy of this licence, visit http://creativecommons.org/licenses/by-nc/4.0/.

\section{References}

1. Matricciani L, Olds T, Petkov J (2012) In search of lost sleep: secular trends in the sleep time of school-aged children and adolescents. Sleep Med Rev 16(3):203-211. https://doi.org/10.1016/j. smrv.2011.03.005

2. Crowley SJ, Van Reen E, LeBourgeois MK, Acebo C, Tarokh L, Seifer R, Barker DH, Carskadon MA (2014) A longitudinal assessment of sleep timing, circadian phase, and phase angle of entrainment across human adolescence. PLoS One 9(11):e112199. https:// doi.org/10.1371/journal.pone.0112199

3. Fricke-Oerkermann L, Pluck J, Schredl M, Heinz K, Mitschke A, Wiater A, Lehmkuhl G (2007) Prevalence and course of sleep problems in childhood. Sleep 30(10):1371-1377. https://doi.org/ 10.1093/sleep/30.10.1371

4. Hysing M, Pallesen S, Stormark KM, Lundervold AJ, Sivertsen B (2013) Sleep patterns and insomnia among adolescents: a population-based study. J Sleep Res 22(5):549-556. https://doi. org/10.1111/jsr.12055

5. Hausler N, Marques-Vidal P, Haba-Rubio J, Heinzer R (2019) Does sleep predict next-day napping or does napping influence same-day nocturnal sleep? Results of a population-based ecological momentary assessment study. Sleep Med 61:31-36. https://doi.org/ 10.1016/j.sleep.2019.04.014

6. Paruthi S, Brooks LJ, D'Ambrosio C, Hall WA, Kotagal S, Lloyd RM, Malow BA, Maski K, Nichols C, Quan SF, Rosen CL, Troester MM, Wise MS (2016) Recommended amount of sleep for pediatric populations: a consensus statement of the american Academy of Sleep Medicine. J Clin Sleep Med 12(6):785-786. https://doi.org/10.5664/jcsm.5866

7. Potter GD, Skene DJ, Arendt J, Cade JE, Grant PJ, Hardie LJ (2016) Circadian rhythm and sleep disruption: causes, metabolic consequences, and countermeasures. Endocr Rev 37(6):584-608. https://doi.org/10.1210/er.2016-1083
8. Kuriyama N, Inaba M, Ozaki E, Yoneda Y, Matsui D, Hashiguchi K, Koyama T, Iwai K, Watanabe I, Tanaka R, Omichi C, Mizuno S, Kurokawa M, Horii M, Niwa F, Iwasa K, Yamada S, Watanabe Y (2017) Association between loss of bone mass due to short sleep and leptin-sympathetic nervous system activity. Arch Gerontol Geriatr 70:201-208. https://doi.org/10.1016/j.archger.2017.02.005

9. Irwin MR, Olmstead R, Carroll JE (2016) Sleep disturbance, sleep duration, and inflammation: a systematic review and meta-analysis of cohort studies and experimental sleep deprivation. Biol Psychiatry 80(1):40-52. https://doi.org/10.1016/j.biopsych.2015. 05.014

10. Krietsch KN, Chardon ML, Beebe DW, Janicke DM (2019) Sleep and weight-related factors in youth: a systematic review of recent studies. Sleep Med Rev 46:87-96. https://doi.org/10.1016/j.smrv. 2019.04.010

11. Wang D, Ruan W, Peng Y, Li W (2018) Sleep duration and the risk of osteoporosis among middle-aged and elderly adults: a doseresponse meta-analysis. Osteoporos Int 29(8):1689-1695. https:// doi.org/10.1007/s00198-018-4487-8

12. Lucassen EA, de Mutsert R, le Cessie S, Appelman-Dijkstra NM, Rosendaal FR, van Heemst D, den Heijer M, Biermasz NR (2017) Poor sleep quality and later sleep timing are risk factors for osteopenia and sarcopenia in middle-aged men and women: the NEO study. PLoS One 12(5):e0176685. https://doi.org/10.1371/ journal.pone. 0176685

13. Sasaki N, Fujiwara S, Yamashita H, Ozono R, Teramen K, Kihara $\mathrm{Y}$ (2016) Impact of sleep on osteoporosis: sleep quality is associated with bone stiffness index. Sleep Med 25:73-77. https://doi.org/ 10.1016/j.sleep.2016.06.029

14. Weaver CM, Gordon CM, Janz KF, Kalkwarf HJ, Lappe JM, Lewis R, O'Karma M, Wallace TC, Zemel BS (2016) The National Osteoporosis Foundation's position statement on peak bone mass development and lifestyle factors: a systematic review and implementation recommendations. Osteoporos Int 27(4):1281-1386. https://doi.org/10.1007/s00198-015-3440-3

15. Casazza K, Hanks LJ, Fernandez JR (2011) Shorter sleep may be a risk factor for impaired bone mass accrual in childhood. J Clin Densitom 14(4):453-457. https://doi.org/10.1016/j.jocd.2011.06. 005

16. Nakagi $Y$, Ito T, Hirooka $\mathrm{K}$, Sugioka $\mathrm{Y}$, Endo H, Saijo $\mathrm{Y}$, Imai H, Takeda H, Kayama F, Sasaki S, Yoshida T (2010) Association between lifestyle habits and bone mineral density in Japanese juveniles. Environ Health Prev Med 15(4):222-228. https://doi.org/10. 1007/s12199-009-0131-8

17. Taylor RW, Haszard JJ, Meredith-Jones KA, Galland BC, Heath AM, Lawrence J, Gray AR, Sayers R, Hanna M, Taylor BJ (2018) 24-h movement behaviors from infancy to preschool: crosssectional and longitudinal relationships with body composition and bone health. Int J Behav Nutr Phys Act 15(1):118. https://doi. org/10.1186/s12966-018-0753-6

18. Ahrens W, Siani A, Adan R, De Henauw S, Eiben G, Gwozdz W, Hebestreit A, Hunsberger M, Kaprio J, Krogh V, Lissner L, Molnar D, Moreno LA, Page A, Pico C, Reisch L, Smith RM, Tornaritis M, Veidebaum T, Williams G, Pohlabeln H, Pigeot I, consortium IF (2017) Cohort profile: the transition from childhood to adolescence in European children-how I.Family extends the IDEFICS cohort. Int J Epidemiol 46(5):1394-1395j. https://doi.org/10.1093/ije/ dyw317

19. Hirshkowitz M, Whiton K, Albert SM, Alessi C, Bruni O, DonCarlos L, Hazen N, Herman J, Adams Hillard PJ, Katz ES, Kheirandish-Gozal L, Neubauer DN, O'Donnell AE, Ohayon M, Peever J, Rawding R, Sachdeva RC, Setters B, Vitiello MV, Ware JC (2015) National Sleep Foundation's updated sleep duration recommendations: final report. Sleep Health 1(4):233-243. https://doi. org/10.1016/j.sleh.2015.10.004 
20. Magee CA, Robinson L, Keane C (2017) Sleep quality subtypes predict health-related quality of life in children. Sleep Med 35:6773. https://doi.org/10.1016/j.sleep.2017.04.007

21. UNESCO Institute for Statistics (2012) International standard classification of education: ISCED 2011. UNESCO Institute for Statistics, Montreal

22. Saraff V, Shaw N (2016) Sunshine and vitamin D. Arch Dis Child 101(2):190-192. https://doi.org/10.1136/archdischild-2014307214

23. Herrmann D, Intemann T, Lauria F, Marild S, Molnar D, Moreno LA, Sioen I, Tornaritis M, Veidebaum T, Pigeot I, Ahrens W, consortium I (2014) Reference values of bone stiffness index and C-terminal telopeptide in healthy European children. Int $\mathrm{J}$ Obes 38(Suppl 2):S76-S85. https://doi.org/10.1038/ijo.2014.138

24. Baroncelli GI (2008) Quantitative ultrasound methods to assess bone mineral status in children: technical characteristics, performance, and clinical application. Pediatr Res 63(3):220-228. https://doi.org/10.1203/PDR.0b013e318163a286

25. Cole TJ, Lobstein T (2012) Extended international (IOTF) body mass index cut-offs for thinness, overweight and obesity. Pediatr Obes 7(4):284-294. https://doi.org/10.1111/j.2047-6310.2012. 00064.x

26. Holm S (1979) A simple sequentially rejective multiple test procedure. Scand J Stat 6:65-70

27. Cheng L, Pohlabeln H, Ahrens W, Lauria F, Veidebaum T, Chadjigeorgiou C, Molnár D, Eiben G, Michels N, Moreno LA, Page AS, Pitsiladis Y, Hebestreit A (2020) Cross-sectional and longitudinal associations between physical activity, sedentary behaviour and bone stiffness index across weight status in European children and adolescents. Int J Behav Nutr Phys Act 17(1):54. https://doi.org/10.1186/s12966-020-00956-1

28. Herrmann D, Buck C, Sioen I, Kouride Y, Marild S, Molnar D, Mouratidou T, Pitsiladis Y, Russo P, Veidebaum T, Ahrens W, consortium I (2015) Impact of physical activity, sedentary behaviour and muscle strength on bone stiffness in 2-10-year-old children-cross-sectional results from the IDEFICS study. Int $\mathbf{J}$ Behav Nutr Phys Act 12:112. https://doi.org/10.1186/s12966-0150273-6

29. McCloskey EV, Kanis JA, Odén A, Harvey NC, Bauer D, González-Macias J, Hans D, Kaptoge S, Krieg MA, Kwok T, Marin F, Moayyeri A, Orwoll E, Gluër C, Johansson H (2015) Predictive ability of heel quantitative ultrasound for incident fractures: an individual-level meta-analysis. Osteoporos Int 26(7): 1979-1987. https://doi.org/10.1007/s00198-015-3072-7

30. Guglielmi G, de Terlizzi F (2009) Quantitative ultrasond in the assessment of osteoporosis. Eur J Radiol 71(3):425-431. https:// doi.org/10.1016/j.ejrad.2008.04.060

31. Gonnelli S, Cepollaro C, Montagnani A, Martini S, Gennari L, Mangeri M, Gennari C (2002) Heel ultrasonography in monitoring alendronate therapy: a four-year longitudinal study. Osteoporos Int 13(5):415-421. https://doi.org/10.1007/s001980200048

32. Sahota O, San P, Cawte SA, Pearson D, Hosking DJ (2000) A comparison of the longitudinal changes in quantitative ultrasound with dual-energy X-ray absorptiometry: the four-year effects of hormone replacement therapy. Osteoporos Int 11(1):52-58. https://doi.org/10.1007/s001980050006
33. Chen G, Chen L, Wen J, Yao J, Li L, Lin L, Tang K, Huang H, Liang J, Lin W, Chen H, Li M, Gong X, Peng S, Lu J, Bi Y, Ning G (2014) Associations between sleep duration, daytime nap duration, and osteoporosis vary by sex, menopause, and sleep quality. J Clin Endocrinol Metab 99(8):2869-2877. https://doi.org/10.1210/jc. 2013-3629

34. Saetung S, Reutrakul S, Chailurkit LO, Rajatanavin R, Ongphiphadhanakul B, Nimitphong H (2018) The association between daytime napping characteristics and bone mineral density in elderly thai women without osteoporosis. Sci Rep 8(1):10016. https://doi.org/10.1038/s41598-018-28260-w

35. Yamada T, Shojima N, Yamauchi T, Kadowaki T (2016) J-curve relation between daytime nap duration and type 2 diabetes or metabolic syndrome: a dose-response meta-analysis. Sci Rep 6:38075. https://doi.org/10.1038/srep38075

36. Yamada T, Hara K, Shojima N, Yamauchi T, Kadowaki T (2015) Daytime napping and the risk of cardiovascular disease and allcause mortality: a prospective study and dose-response meta-analysis. Sleep 38(12):1945-1953. https://doi.org/10.5665/sleep.5246

37. Jakubowski KP, Hall MH, Marsland AL, Matthews KA (2016) Is daytime napping associated with inflammation in adolescents? Health Psychol 35(12):1298-1306. https://doi.org/10.1037/ hea0000369

38. Chaput JP, Dutil C, Sampasa-Kanyinga H (2018) Sleeping hours: what is the ideal number and how does age impact this? Nat Sci Sleep 10:421-430. https://doi.org/10.2147/NSS.S163071

39. Zeng Y, Wu J, Yin J, Chen J, Yang S, Fang Y (2018) Association of the combination of sleep duration and sleep quality with quality of life in type 2 diabetes patients. Qual Life Res 27(12):3123-3130. https://doi.org/10.1007/s11136-018-1942-0

40. Staab JS, Smith TJ, Wilson M, Montain SJ, Gaffney-Stomberg E (2019) Bone turnover is altered during $72 \mathrm{~h}$ of sleep restriction: a controlled laboratory study. Endocrine 65(1):192-199. https://doi. org/10.1007/s12020-019-01937-6

41. Swanson CM, Shea SA, Wolfe P, Cain SW, Munch M, Vujovic N, Czeisler CA, Buxton OM, Orwoll ES (2017) Bone turnover markers after sleep restriction and circadian disruption: a mechanism for sleep-related bone loss in humans. J Clin Endocrinol Metab 102(10):3722-3730. https://doi.org/10.1210/jc.2017-01147

42. Master L, Nye RT, Lee S, Nahmod NG, Mariani S, Hale L, Buxton OM (2019) Bidirectional, daily temporal associations between sleep and physical activity in adolescents. Sci Rep 9(1):7732. https://doi.org/10.1038/s41598-019-44059-9

43. Buysse DJ (2014) Sleep health: can we define it? Does it matter? Sleep 37(1):9-17. https://doi.org/10.5665/sleep.3298

44. Perrini S, Laviola L, Carreira MC, Cignarelli A, Natalicchio A, Giorgino F (2010) The GH/IGF1 axis and signaling pathways in the muscle and bone: mechanisms underlying age-related skeletal muscle wasting and osteoporosis. J Endocrinol 205(3):201-210. https://doi.org/10.1677/joe-09-0431

45. Leproult R, Copinschi G, Buxton O, Van Cauter E (1997) Sleep loss results in an elevation of cortisol levels the next evening. Sleep 20(10):865-870

Publisher's note Springer Nature remains neutral with regard to jurisdictional claims in published maps and institutional affiliations. 